\title{
Evidence of Tumour Microenvironment and Stromal Cellular Components in Retinoblastoma
}

\author{
Rajeswari Raguraman ${ }^{a, c}$ Sowmya Parameswaran ${ }^{b}$ Jagat Rakesh Kanwar ${ }^{c}$ \\ Vikas Khetan ${ }^{d}$ Pukhraj Rishid Rupinder Kaur Kanwar ${ }^{\mathrm{c}}$ \\ Subramanian Krishnakumar ${ }^{\mathrm{a}, \mathrm{c}}$ \\ a Department of Larsen and Toubro Ocular Pathology, Vision Research Foundation, Sankara Nethralaya, Chennai, India; \\ ${ }^{\mathrm{b}}$ Radheshyam Kanoi Stem Cell Laboratory, Vision Research Foundation, Sankara Nethralaya, Chennai, India; ' School \\ of Medicine, Centre for Molecular and Medical Research, Deakin University, Geelong, VIC, Australia; ${ }^{d}$ Department of \\ Ocular Oncology, Medical Research Foundation, Sankara Nethralaya, Chennai, India
}

\section{Keywords}

Retinoblastoma $\cdot$ Stromal cells $\cdot$ Tumour

microenvironment · Endothelial cells · Fibroblasts .

Tumour-associated macrophages

\begin{abstract}
Background: The tumour microenvironment (TME) consisting of tumour cells and multiple stromal cell types regulate tumour growth, invasion and metastasis. While the concept of TME and presence of stromal cellular components is widely established in cancers, its significance in the paediatric intraocular malignancy, retinoblastoma (RB), remains unknown. Methods: The study qualitatively identified the presence of multiple stromal cellular subtypes in RB TME by immunohistochemistry. Results: Results of the study identified the presence of stromal cell types such as endothelial cells, tumour-associated macrophages, fibroblasts, cancerassociated fibroblasts, retinal astrocytes and glia in RB TME. The extent of stromal marker positivity, however, did not correlate with histopathological features of RB. Conclusions: The findings of the study convincingly suggest the presence
\end{abstract}

\section{KARGER}

() 2018 S. Karger AG, Basel

E-Mail karger@karger.com

www.karger.com/oop of a stromal component in RB tumours. The interactions between stromal cells and tumour cells might be of profound importance in RB progression.

(c) 2018 S. Karger AG, Basel

\section{Introduction}

Retinoblastoma (RB) caused by the mutation in the RB1 gene [1,2] and amplification of N-Myc gene [3] has an incidence of about 9,000 cases every year worldwide [4]. Primary therapeutic modalities used for RB majorly include chemotherapy via systemic, intra-arterial, intravitreal, periocular routes and are supported by focal therapy [5-9]. Limitations associated with chemotherapy include the development of drug resistance and other secondary complications $[5,10,11]$.

Dr. Subramanian Krishnakumar

Department of Larsen and Toubro Ocular Pathology

Kamalnayan Bajaj Vision Research Foundation, Old No. 18

New No. 41, College Road, Chennai, Tamil Nadu 600006 (India)

E-Mail drkrishnakumar_2000@yahoo.com

Dr. Rupinder Kaur Kanwar

School of Medicine, Centre for Molecular and Medical Research

Deakin University, Locked Bag 20000

Geelong VIC, 3220 (Australia)

E-Mail rupinder.kanwar@ deakin.edu.au 
The complex mechanisms of chemoresistance observed in tumour cells are now being attributed to the interactions occurring in the tumour microenvironment (TME) [12]. Components of TME comprising tumour cells, immune cells and other stromal cells along with their vital interactions contribute to treatment response and disease prognosis. Accumulating evidence in both epithelial [13-16] and neural cancers [17, 18] suggest a close interplay between the tumour and niche involving non-neoplastic components to secrete signalling molecules, growth factors that contribute to increased angiogenesis, invasion, progression and metastasis [19-23]. The TME components are hence referred to as "partners in crime" for the tumourigenesis process [24, 25].

In addition to providing mechanistic insight into tumourigenesis, the knowledge on stromal components may also have direct clinical implications, since the role of the stroma is context-specific. For instance, in pancreatic cancers, several targeted therapies have failed during the clinical trials due to the presence of a highly heterogenous and thick stromal microenvironment. It is suggested that, while on the one hand the stromal microenvironment restrains the tumour and prevents the metastasis, on the other hand, it also prevents most drugs from penetrating [26]. Therapies targeting stromal components are being considered, and this does not compromise the restraining part of the stroma while allowing the drugs to penetrate efficiently. The stromal cell populations in the tumour were studied using a long-term spinning disk confocal microscopy technique. Results showed stromal cells population to be more dynamic and evolving as the tumourigenesis progressed. This directly relates to the effect of therapies during stages of the tumour development. In addition to the tumour cells, the evaluation of the stromal microenvironment during pre-treatment, treatment and posttreatment may hence be required to decide on an ideal therapeutic regimen [27]. Emerging live imaging techniques such as diffusion-weighted imaging, which measures the mobility of water in the tumour tissue can aid in predicting the differences in the stromal microenvironment [28]. Hence, understanding the components of stromal microenvironment might be of great help in prognosticating the tumours and customizing therapies.

Studies on TME and its associated stromal components are well established in most epithelial cancers [23, 29]. The presence of this stromal component in the epithelial cancers is expected due to the virtue of the primary tissue that undergoes a transformation. On the other hand, as commented by Cobrinik, for neural cancer like $\mathrm{RB}$, the malignancy is understood to arise from the cone photoreceptors of the retina [30] that contains an exceptionally high density of microvessels. The tumour development thus occurs conjointly with vascular development in the retina. During the developmental stages, these retinal vasculatures undergo extensive remodelling and maturation, which is reported to contribute to the invasive abilities of tumour cells [31].

The neural tissue, unlike the epithelial tissue, is devoid of stromal components, and hence, it has been difficult to establish the presence or a role for a stromal tissue in RB. In addition to the cell of origin and observed loss of $\mathrm{RB}$ function, it is now being recognized that the retinal microenvironment contributes extensively to tumourigenesis [32]. When looking at the presence of stromal cellular subtypes in $\mathrm{RB}$, reports suggest the retinal glial cells (both normal retina and tumour-derived) [32], tumour-associated macrophages (TAMs) and pericytes $[33,34]$ contribute to RB tumourigenesis by promoting cell proliferation and survival. Findings of cultured tumourspheres and not adherent stromal cells showing RB1 mutation also supported the existence of distinct tumour and stromal components in RB [35]. These existing studies, however, were restricted to the identification of particular cell types such as macrophages and glia and did not provide a holistic view of components in RB TME.

Considering that there is a very little understanding about interactions between tumour cells and non-neoplastic cells in RB, the current study was designed to characterize the cellular TME components seen in RB tumours. This study emphasizes the presence of multiple stromal cell types, which probably by the interaction with $\mathrm{RB}$ tumour cells contributes to tumourigenesis. A correlation of stromal cell levels in RB tumours and retina samples would help in a better understanding of the stages of tumour development and disease prognosis. The findings of this study in a broader perspective may be used to tailor novel anti-cancer therapies targeted towards RB tumour stroma or provide decision support in a clinical setting for effective management of RB.

\section{Methodology}

Sample Collection and Ethics Approval

The study was reviewed and approved by the local Ethics Committee at Vision Research Foundation, Sankara Nethralaya (Ethics number: 246-2011-P), Chennai, India and the committee deemed that it conformed to the generally accepted principles of research, in accordance with the Helsinki Declaration. This study was exempted from ethics review and was found to comply with the National Statement on Ethical Conduct in Human Research (2007) by the Human
86

Ocul Oncol Pathol 2019;5:85-93 DOI: $10.1159 / 000488709$
Raguraman/Parameswaran/Kanwar/ Khetan/Rishi/Kanwar/Krishnakumar 
Table 1. Histopathological features of RB tumours used in the study $(n=12)$

\begin{tabular}{|c|c|c|c|c|c|c|}
\hline S. No & Age/sex & Laterality & $\begin{array}{l}\text { IIRC } \\
\text { group }\end{array}$ & Histopathological features & $\begin{array}{l}\text { Invasive } \\
\text { status }\end{array}$ & $\begin{array}{l}\text { Chemotherapy } \\
\text { details }\end{array}$ \\
\hline RB1 & 2 years/male & OS & $\mathrm{D}$ & $\begin{array}{l}\mathrm{RB}, \mathrm{PD} \text {, invasion of the choroid measuring }>3 \mathrm{~mm} \text {, } \\
\text { pre-laminar invasion of the optic nerve }\end{array}$ & Yes & $\begin{array}{l}14 \text { cycles post } \\
\text { enucleation }\end{array}$ \\
\hline RB2 & 2 years/female & OD & $\mathrm{E}$ & $\begin{array}{l}\mathrm{RB}, \mathrm{WD} \text {, choroidal invasion }>3 \mathrm{~mm} \text {, pre-laminar } \\
\text { invasion of optic nerve seen }\end{array}$ & Yes & $\begin{array}{l}2 \text { cycles post } \\
\text { enucleation }\end{array}$ \\
\hline RB4 & 4 years/female & $\mathrm{OD}$ & $\mathrm{E}$ & $\begin{array}{l}\mathrm{RB}, \mathrm{PD} \text {, choroidal invasion }>3 \mathrm{~mm} \text {, pre-laminar, } \\
\text { laminar and post-laminar invasion of optic nerve seen }\end{array}$ & Yes & $\begin{array}{l}6 \text { cycles chemo } \\
\text { post enucleation }\end{array}$ \\
\hline RB5 & 1 years/female & OD & $\mathrm{E}$ & $\begin{array}{l}\mathrm{RB}, \mathrm{WD} \text {, focal invasion of choroid }<3 \mathrm{~mm} \text {, there is no } \\
\text { laminar and post-laminar invasion of optic nerve }\end{array}$ & Yes & NC \\
\hline RB8 & 3 years/male & OS & $\mathrm{E}$ & RB, WD, no choroidal and optic nerve invasion & No & NC \\
\hline RB9 & 5 years/female & $\mathrm{OD}$ & $\mathrm{D}$ & $\mathrm{RB}, \mathrm{PD}$, no choroidal and optic nerve invasion & No & NC \\
\hline RB10 & 3 years $/$ male & OS & $\mathrm{E}$ & $\mathrm{RB}, \mathrm{PD}$, no invasion of choroid, and optic nerve & No & $\mathrm{NC}$ \\
\hline RB11 & $\begin{array}{l}3 \text { months/ } \\
\text { male }\end{array}$ & OS & $\mathrm{E}$ & $\mathrm{RB}, \mathrm{WD}$, no invasion of choroid and optic nerve & No & NC \\
\hline $\mathrm{RB} 12$ & 2 years/male & OS & $\mathrm{E}$ & $\mathrm{RB}, \mathrm{WD}$, no invasion of choroid, and optic nerve & No & $\mathrm{NC}$ \\
\hline
\end{tabular}

Histopathological features of RB samples used in the study $(n=12)$.

$\mathrm{RB}$, retinoblastoma; IIRC, international intraocular retinoblastoma classification; OS, left eye; OD, right eye; OU, both eyes; PD, poorly differentiated; WD, well differentiated; NC, no chemotherapy; D and E, RB grouping as per IIRC. Chemotherapy using a combination of drugs, namely, carboplatin, etoposide, vincristine and melphalan was administered post enucleation.

Research Ethics Committee at Deakin University (DUHREC approval number 2017-219). Tumour samples were obtained from patients who underwent therapeutic enucleation for RB management. Twelve RB tumours post enucleation received at the L \& T Ocular Pathology laboratory between the years 2011 and 2013 were used in the study (histopathological details compiled in Table 1). Informed written consent on the use of these tissues for research purposes was obtained as part of the regular consent during surgery.

Haematoxylin and Eosin ( $H$ and E) Staining of $R B$

Tumour Tissue Sections

$\mathrm{H}$ and $\mathrm{E}$ staining of formalin fixed paraffin embedded (FFPE) sections of RB tumours was performed using standard procedures.

\section{Immunohistochemistry}

Immunohistochemistry (IHC) was used for the qualitative estimation of cluster of differentiation (CD)31 (mouse monoclonal antibody, clone JC70A, Dako, Copenhagen, Denmark; endothelial cell - EC marker), CD68 (mouse monoclonal antibody, clone KP1, Pathnsitu Biotechnologies, Hyderabad; TAM marker), alpha smooth muscle actin ( $\alpha$-SMA; mouse monoclonal antibody, clone 1A4 Dako, Copenhagen, Denmark), (cancer associated fibroblasts [CAFs] marker), vimentin (mouse monoclonal antibody, clone V9, Dako, Copenhagen, Denmark; fibroblasts marker) and synaptophysin (Rabbit monoclonal antibody antibody, clone GR007, Pathnsitu Biotechnologies, Hyderabad; neuroendocrine marker) on FFPE sections of RB tumours $(n=12)$ and associated normal retina. For all the antibodies, the process of antigen retrieval and staining were performed on the Bench Mark GX (Ventana, Roche) automatic devices and antibody positivity was visualised with HRP-conjugated secondary antibodies (Sigma Aldrich). Bound peroxidase was detected with 3,3'diaminobenzidine (Sigma Aldrich) and counterstained with Mayer's haematoxylin (Sigma Aldrich). Both the central portion of the tumour and pathologically assessed areas of RB tumour cell invasion, namely, the choroid and optic nerve were included in the study. Placental tissue (CD31), reactive lymphoid follicle (CD68), leiomyoma uterus ( $\alpha$-SMA), colon (vimentin) and pancreatic (synaptophysin) tissue sections obtained from SM Surgipath laboratories, Chennai, India, were used as positive controls. All stained specimens were analysed under a light microscope (Nikon Eclipse Ci-L, 
Tokyo, Japan) and further reviewed in the presence of 2 pathologists blinded to clinical data. Discrepancies if any were resolved by simultaneous viewing with a multiheaded microscope.

\section{Results}

Histopathological Features of RB Tumours $(n=12)$

The histopathological features of RB tumours used in the study are summarized in Table 1 . Patient cohort consisted of 6 males and 6 females and mean age of the patients was 2.41 years.

\section{$H$ and E Staining Identifies the Existence of \\ Stromal Regions in $R B$}

$\mathrm{H}$ and $\mathrm{E}$ staining revealed $\mathrm{RB}$ tumours to contain both cellular and necrotic areas (Fig. 1a). The cellular areas contained tumour cells arranged as lobules around blood vessels. The vascular channels present in the tumours showed 2 distinct patterns. While the first type of vascular channels did not show extracellular matrix (ECM) depo- sition (Fig. 1b), the second pattern has deposition of ECM around them (Fig. 1c). The tumour cells showed the invasion of choroid (Fig. 1d) or optic nerve or both. While regions depicted in Fig. 1a-c were seen in all 12 cases analyzed, only RB tumours with invasion $(n=6)$ showed the features represented in Fig. 1d. The diverse stromal cellular subtypes in the RB tumour tissues were further qualitatively explored in the RB tumour sections using IHC.

\section{Expression Pattern of Stromal Markers in RB Tumour and Associated Normal Retina Sections}

The expression pattern of stromal markers CD31, CD68, a-SMA, vimentin and synaptophysin was evaluated in FFPE sections of RB tumours (6 invasive and 6 non-invasive cases, histopathological features provided in Table 1) and associated retina sections. The retina sections were microscopically observed to be devoid of tumour cells. Representative IHC images of markers staining in $2 \mathrm{RB}$ tumours, a retina section and positive control are compiled in Figure 2.
Fig. 1. $\mathrm{H}$ and $\mathrm{E}$ staining reveals the presence of stromal regions in FFPE sections of an invasive RB tumour (Patient-RB1; Table 1). The $\mathrm{H}$ and $\mathrm{E}$ staining reveals the presence of (a) necrotic areas, (b) tumour lobules with blood vessels without ECM deposition, (c) tumour lobules with central blood vessels and regions of ECM deposition and (d) tumour cells invasion into the choroid. Magnification: $20 \times$. RB, retinoblastoma; FFPE, formalin fixed paraffin embedded tissue; ECM, extracellular matrix.
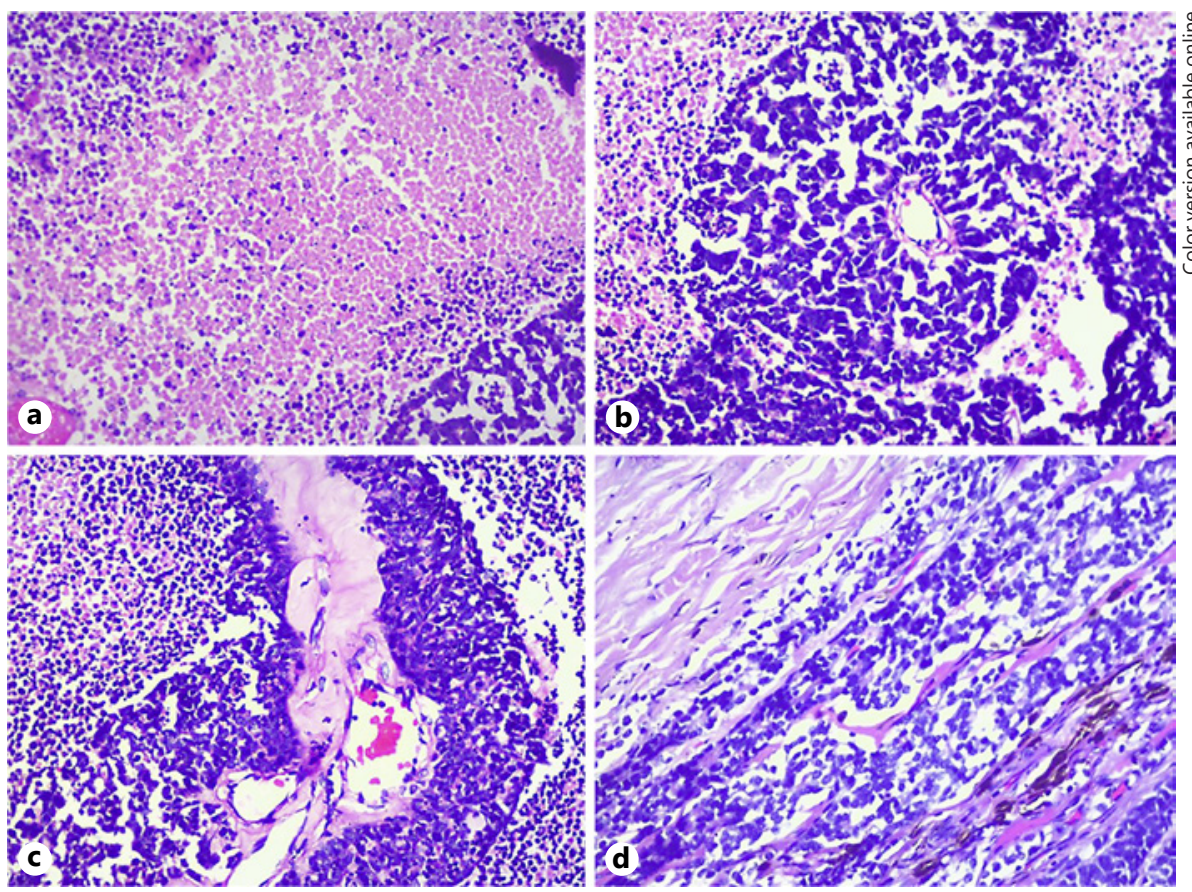

Fig. 2. Expression of stromal cellular markers in FFPE sections of RB tumours and retina. Representative images of (a-d) CD 31 staining, (e-h) CD 68 staining (i-I) vimentin staining, $(\mathbf{m}-\mathbf{p})$ a-SMA staining, (q-t) synaptophysin in non-invasive RB tumour, invasive $\mathrm{RB}$ tumour, retinal tissue section and positive control respectively. Positive controls: placental tissue $(\mathbf{d})$, reactive lym- phoid follicular tissue (h), colon tissue (I), leiomyoma uterine tissue (p), pancreatic tissue (t). Magnification: $20 \times$. CD, cluster of differentiation; TAM, tumour associated macrophages; FFPE, formalin fixed paraffin embedded; $\alpha$-SMA, alpha smooth muscle actin; CAFs, cancer associated fibroblasts; RB, retinoblastoma.

(For figure 2 see next page.)
Ocul Oncol Pathol 2019;5:85-93

DOI: $10.1159 / 000488709$
Raguraman/Parameswaran/Kanwar/ Khetan/Rishi/Kanwar/Krishnakumar 

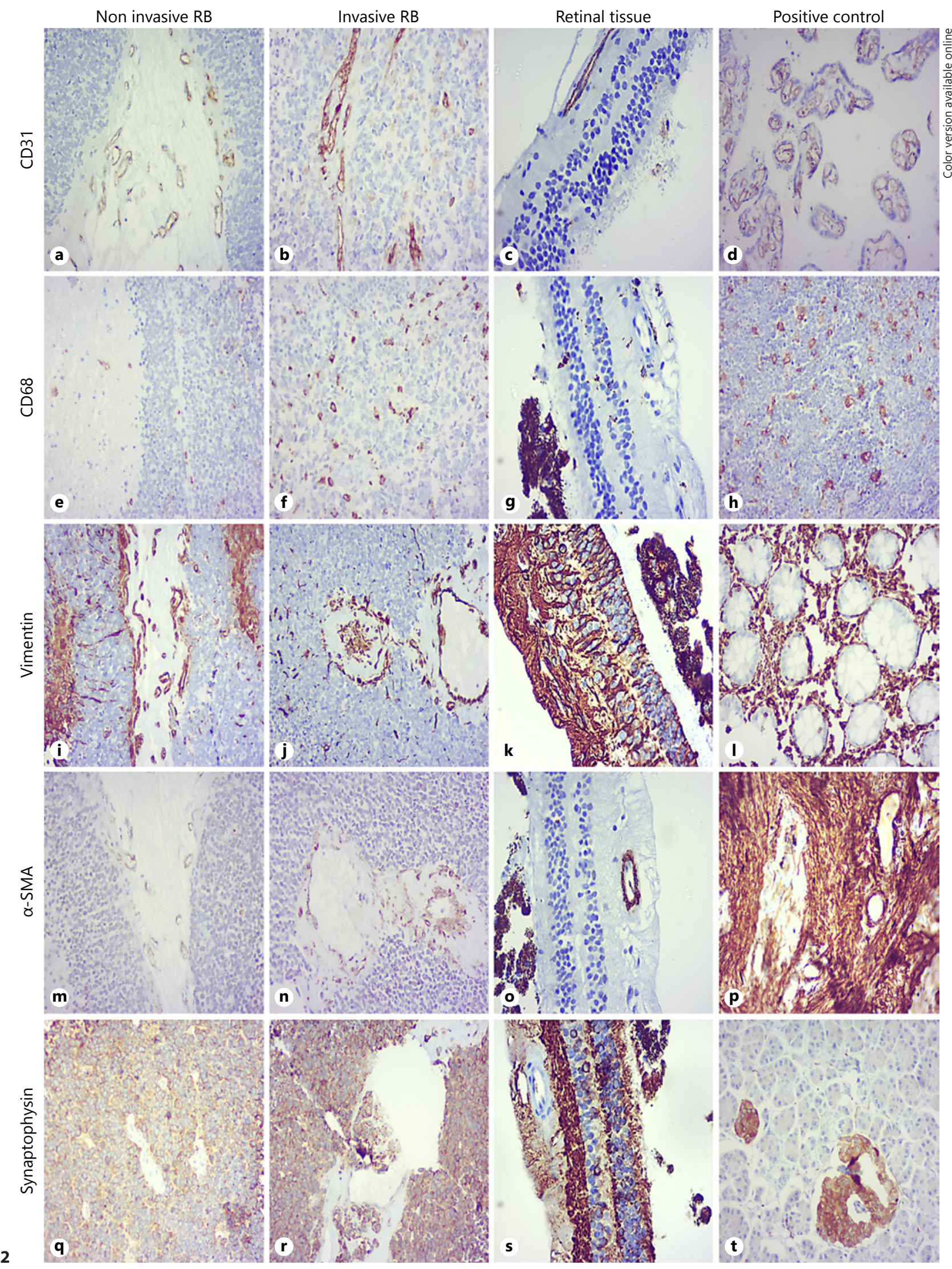


\section{CD31 Expression in $R B$}

The presence of ECs as marked by moderate to strong positivity to CD31 was observed near blood vessels and ECM compartment of RB tumours (Fig. 2a, b). A weak positivity to $\mathrm{CD} 31$ was also found in the retina tissue (Fig. 2c). Placental tissue sections were employed as a positive control for immunoreactivity of CD31 antibody (Fig. 2d).

\section{CD68 Expression in $R B$}

TAMs, as identified by the positivity to CD68 marker, were found scattered in the necrotic regions and ECM regions of RB tumours (Fig. 2e, f). The presence of macrophages was also found in the retina tissue section (Fig. $2 \mathrm{~g}$ ). Reactive lymphoid follicular tissue was included as the positive control for anti-CD68 antibody staining (Fig. 2h).

\section{Expression of Vimentin in $R B$}

Moderate to high positivity of vimentin was seen in blood vessels and ECM of RB tumours. Positivity to vimentin is suggestive of the presence of cell types such as fibroblasts, CAFs, mesenchymal stem cells and glial cells (Fig. 2i, j). Retinal tissue also showed a strong positivity to vimentin (Fig. 2k). Colon tissue sections were employed as a positive control for antibody immunoreactivity (Fig. 2l).

\section{$\alpha$-SMA Expression in $R B$}

Weak to moderate staining of $\alpha$-SMA suggestive of the presence of fibroblasts and CAFs was observed in RB tumours. The fibroblast population was localized near the blood vessels and the ECM (Fig. $2 \mathrm{~m}$, n). Leiomyoma uterine tissue was stained as a positive control for the presence of $\alpha$-SMA positive cells (Fig. 2p).

\section{Synaptophysin Expression in $R B$}

RB tumour cells showed a strong membrane positivity to synaptophysin (Fig. 2q, r). Positivity of tumour cells to synaptophysin supports the fact that these tumourigenic cells are of neural origin. In contrast to the strong positivity seen in the tumour cells, synaptophysin expression was negative in the stromal areas. The retina also showed positivity to synaptophysin (Fig. 2s). Pancreatic tissue was used as a positive control for the experiment (Fig. 2t).

Taken together, the IHC results for stromal markers in RB FFPE sections revealed the existence of several stromal cell types such as ECs (CD31+), TAMs (CD68+), fibroblasts, mesenchymal stem cells, retinal glia (Vim+), CAFs $(a-S M A+)$. Characteristic distribution of these stromal cell types was observed in the TME of RB tumours with ECs predominant in the blood vessels and TAMs near necrotic areas or at actively proliferating tumour sites. In all the tumours, fibroblasts were widely distributed with a lesser expression of CAFs. Conversely, synaptophysin expression was confined to the tumour cells of RB and not in the stromal areas. The extent of stromal markers positivity varied between the tumours and did not correlate with histopathological features (invasive or differentiation status) of RB.

\section{Discussion}

The role of TME, its associated cellular, non-cellular components have been well studied in detail in various types of adult-onset epithelial cancers [23, 29] and some paediatric cancers such as neuroblastoma and medulloblastoma [17, 36, 37]. Contrarily, very few studies outline the existence of TME in RB [32-35]. The results of the current study confirm the presence of multiple stromal cell types in RB TME akin to the ones observed in other cancer types.

The TME in any tumour comprises rapidly proliferating tumour cells, stromal cells, inflammatory cells, blood vessels and other tissue-associated cells. A study by Houston et al. [38] had earlier detected stromal components of RB TME in a transgenic model of RB, human RB tissue samples and investigated changes in gene expression patterns in different areas of tumours in murine models. These studies emphasized upon the tumour heterogeneity and the TME component further suggesting a focus on stromal components for improving RB tumour management. The current study hence aimed to explore the presence of stromal cell types, namely, ECs, fibroblasts, CAFs and mesenchymal stem cells in RB TME. The presence of each cell type is characterized by positivity to markers [39], the interpretation of marker positivity in RB TME is provided in detail in Table 2.

While the ECs help in the formation of new blood vessels to assist tumour growth and metastasis [40], fibroblasts, CAFs secrete growth factors $[41,42]$ and contribute to ECM remodelling. The presence of ECs as revealed by positivity to CD31 marker was identified in all the 12 RB tumours assessed, and these cells were majorly found localised in the blood vessels of RB tumours. The positivity to CD31 in the retina could be contributed by the presence of choroidal and retinal ECs. The presence of these ECs in RB stroma is believed to favour tumour growth by supplying abundant growth factors via the blood-retinal
90

Ocul Oncol Pathol 2019;5:85-93 DOI: $10.1159 / 000488709$
Raguraman/Parameswaran/Kanwar/ Khetan/Rishi/Kanwar/Krishnakumar 
Table 2. Interpretation of stromal cellular components in RB as stained by various IHC markers

\begin{tabular}{|c|c|c|c|c|c|c|}
\hline \multirow{3}{*}{$\begin{array}{l}\text { Marker used } \\
\text { for the study }\end{array}$} & \multirow[t]{3}{*}{ Positive control } & \multicolumn{5}{|c|}{ Localization in RB FFPE sections } \\
\hline & & \multirow{2}{*}{$\begin{array}{l}\text { tumour } \\
\text { region }\end{array}$} & \multicolumn{4}{|l|}{ RB stromal areas } \\
\hline & & & $\begin{array}{l}\text { stromal basement } \\
\text { membrane like material }\end{array}$ & $\begin{array}{l}\text { fibroblasts, CAFs } \\
\text { and muller glial cells }\end{array}$ & macrophages & $\begin{array}{l}\text { endothelial } \\
\text { cells }\end{array}$ \\
\hline CD31 & Placenta & + & - & - & - & + \\
\hline CD68 & Reactive lymphoid follicle & - & - & - & + & - \\
\hline a-SMA & Leiomyoma uterus & - & - & + & - & + \\
\hline Vimentin & Colon & - & - & + & - & + \\
\hline Synaptophysin & Pancreas & + & - & - & - & - \\
\hline
\end{tabular}

RB, retinoblastoma; IHC, immunohistochemistry; FFPE, formalin fixed paraffin embedded.

barrier. The study also identified the presence of TAMs in all the 12 RB tumours analysed; however, the intensity of positivity varied between tumours. Observed CD 68 positivity in the normal retina is also suggestive of bloodderived macrophages infiltrating the retinal tissue.

On the other hand, fibroblasts, characterized by positivity to vimentin and $\alpha$-SMA, were the abundant stromal cell type present in RB TME. Positivity to vimentin could also be contributed by the presence of mesenchymal stem cells, macrophages, ECs, pericytes and is suggestive of occurrence of an EMT process [43, 44]. Further, an increased density of CAFs at invasive front is reported to restrict a number of anti-cancer drugs reaching the cell surface [45], and this may be a critical parameter in contributing to drug resistance observed in RB. Analysis of CAF density levels in an additional cohort of drug-resistant tumours would help a better understanding of the role of this cell type in $\mathrm{RB}$ drug resistance. Lastly, the positive expression of synaptophysin was confined to RB tumour cells and not stromal areas, and this suggests that RB is a neuroendocrine tumour.

Stromal cell infiltration levels are indicators of disease prognosis and response to therapy. Reports suggest that a strong macrophage signature in TME is known to stimulate angiogenesis [46], the tumour cell survival [47] in turn attributing to poor disease prognosis [48]. Our study results are consistent with these findings and hint an association between increased macrophage infiltration and tumour progression. The mechanisms of disease promotion by TAMs in RB have not been previously explored and warrant further investigation.

The non-neoplastic cells are less susceptible to mutations when compared to the cancerous cells, and molecules selectively expressed on these cells can serve as attractive targets for therapy. Anti-tumour therapies or drugs targeting TAMs are currently in use for blocking cancer progression [15], and these could also be used for RB management. Earlier studies have identified each RB tumour to behave differently as there exists a difference in regional and temporal difference in gene expression patterns between them [38]. An understanding of underlying TME components is therefore required for the development of novel adjuvant treatments for RB. These multiple cell types seen in RB TME could also contribute to observed angiogenesis and hypoxia, and hence treatment to targeting these stromal cells might provide greater success rates than the ones observed with standard treatment protocols [49]. Given the side effects of systemic chemotherapy and its inhibitory role due to higher tumour stroma [50], wide varieties of local therapies have gained attention in cancer treatment. Reports of better response and fewer side effects with local therapies (intravitreal and intraarterial) have earlier been reported in RB [51-53]. These reports further hint the involvement of stroma in contributing to observed side effects of systemic chemotherapy in RB. The effects of drugs used in local therapies, namely, melphalan on these stromal cells could provide insights on how these drugs affect signalling pathways to result in tumour regression. The findings of the study in a nutshell would open new horizons in defining key events in RB tumour development and response to treatments.

The current study has few limitations; first, about smaller cohort size of RB tumours employed in the study, future quantification studies with increased tumour cohort size would benefit better correlation of the expression patterns of stromal cells to disease staging of patients with RB. At this point, these IHC-based observations do 
not provide a clear understanding of how these stromal components work in synergy with the malignant cells and contribute to $\mathrm{RB}$ progression. Taking leads from these preliminary findings, in vitro RB models could be established to screen potential candidate markers and decipher the critical signalling pathways mediated by tumour-stroma interactions in RB.

Nevertheless, this current study for the first time has identified the presence of multiple stromal cell types in $\mathrm{RB}$ and serves as a proof of concept to establish the fact that $\mathrm{RB}$, like any other epithelial or neural cancer, possesses a TME component. The stromal cellular components of TME along with their vital interactions might contribute to $\mathrm{RB}$ progression.

\section{Acknowledgements}

Deakin University is acknowledged for providing a scholarship to Ms Rajeswari Raguraman under the Deakin India Research Initiative (DIRI, In country $\mathrm{PhD}$ ) Graduate student program (code: H960, Student No. 213390445). We are thankful to Prof. Karen Dwyer, Deputy Head, School of Medicine, Deakin University for critically reviewing the manuscript and her valuable suggestions.

\section{Statement of Ethics}

Informed consents were obtained from the parents/guardians. The study was approved by Human Ethics Committee at the Vision Research Foundation (Ethics number: 246-2011-P) and granted exemption from ethics review by Deakin University Human Research Ethics Committee (DUHREC: approval number 2017-219).

\section{Disclosure Statement}

The authors declare that they have no conflicts of interest to disclose.

\section{Funding Source}

The work was supported with funding received from the Department of Biotechnology, Government of India - grant number $\mathrm{BT} / 01 / \mathrm{CEIB} / 11 / \mathrm{V} / 16$.

\section{References}

1 Minoda K: [Genetics of retinoblastoma]. Nihon Rinsho. Jap JClin Med 1995;53:2774-2778.

2 Lohmann DR: RB1 gene mutations in retinoblastoma. Hum Mutat 1999;14:283-288.

3 Lee WH, Murphree AL, Benedict WF: Expression and amplification of the $\mathrm{N}$-myc gene in primary retinoblastoma. Nature 1984;309: 458-460.

4 Dimaras H, Kimani K, Dimba EA, Gronsdahl P, White A, Chan HS, Gallie BL: Retinoblastoma. Lancet 2012;379:1436-1446.

5 Turaka K, Shields CL, Meadows AT, Leahey A: Second malignant neoplasms following chemoreduction with carboplatin, etoposide, and vincristine in 245 patients with intraocular retinoblastoma. Pediatr Blood Cancer 2012;59:121-125.

6 Shields CL, Fulco EM, Arias JD, Alarcon C, Pellegrini M, Rishi P, Kaliki S, Bianciotto CG, Shields JA: Retinoblastoma frontiers with intravenous, intra-arterial, periocular, and intravitreal chemotherapy. Eye (Lond) 2013;27: 253-264.

7 Shields CL, Manjandavida FP, Lally SE, Pieretti G, Arepalli SA, Caywood EH, Jabbour P, Shields JA: Intra-arterial chemotherapy for retinoblastoma in 70 eyes: outcomes based on the international classification of retinoblastoma. Ophthalmology 2014;121:1453-1460.
8 Francis JH, Brodie SE, Marr B, Zabor EC, Mondesire-Crump I, Abramson DH: Efficacy and toxicity of intravitreous chemotherapy for retinoblastoma: four-year experience. Ophthalmology 2017;124:488-495.

9 Abramson DH: Periocular chemotherapy for retinoblastoma: success with problems? Arch Ophthalmol 2005;123:128-129.

10 Shields CL, Shields JA: Intra-arterial chemotherapy for retinoblastoma: the beginning of a long journey. Clin Exp Ophthalmol 2010;38: 638-643.

11 Shields CL, Manjandavida FP, Arepalli S, Kaliki S, Lally SE, Shields JA: Intravitreal melphalan for persistent or recurrent retinoblastoma vitreous seeds: preliminary results. JAMA Ophthalmol 2014;132:319-325.

12 Senthebane DA, Rowe A, Thomford NE, Shipanga $\mathrm{H}$, Munro D, Mazeedi M, Almazyadi HAM, Kallmeyer K, Dandara C, Pepper MS, Parker MI, Dzobo K: The role of tumor microenvironment in chemoresistance: to survive, keep your enemies closer. Int J Mol Sci 2017;18:pii:E1586.

13 Banat GA, Tretyn A, Pullamsetti SS, Wilhelm J, Weigert A, Olesch C, Ebel K, Stiewe T, Grimminger F, Seeger W, Fink L, Savai R: Immune and inflammatory cell composition of human lung cancer stroma. PLoS One 2015; 10:e0139073.
14 Maturu P, Overwijk WW, Hicks J, Ekmekcioglu S, Grimm EA, Huff V: Characterization of the inflammatory microenvironment and identification of potential therapeutic targets in wilms tumors. Transl Oncol 2014;7:484-492.

15 Mao Y, Keller ET, Garfield DH, Shen K, Wang J: Stromal cells in tumor microenvironment and breast cancer. Cancer Metastasis Rev 2013;32:303-315.

16 Hamada S, Masamune A, Shimosegawa T: Alteration of pancreatic cancer cell functions by tumor-stromal cell interaction. Front Physiol 2013;4:318

17 Hashimoto O, Yoshida M, Koma Y, Yanai T, Hasegawa D, Kosaka Y, Nishimura N, Yokozaki $\mathrm{H}$ : Collaboration of cancer-associated fibroblasts and tumour-associated macrophages for neuroblastoma development. J Pathol 2016;240:211-223.

18 Byrd T, Grossman RG, Ahmed N: Medulloblastoma-biology and microenvironment: a review. Pediatr Hematol Oncol 2012;29:495506.

19 Watnick RS: The role of the tumor microenvironment in regulating angiogenesis. Cold Spring Harb Perspect Med 2012;2: a006676. 
20 Yuan Y, Jiang YC, Sun CK, Chen QM: Role of the tumor microenvironment in tumor progression and the clinical applications (Review). Oncol Rep 2016;35:24992515.

21 Nyberg P, Salo T, Kalluri R: Tumor microenvironment and angiogenesis. Front Biosci 2008;13:6537-6553.

22 Lorusso G, Ruegg C: The tumor microenvironment and its contribution to tumor evolution toward metastasis. Histochem Cell Biol 2008;130:1091-1103.

23 Quail DF, Joyce JA: Microenvironmental regulation of tumor progression and metastasis. Nat Med 2013;19:1423-1437.

24 Moffitt RA, Marayati R, Flate EL, Volmar KE, Loeza SG, Hoadley KA, Rashid NU, Williams LA, Eaton SC, Chung AH, Smyla JK, Anderson JM, Kim HJ, Bentrem DJ, Talamonti MS, Iacobuzio-Donahue CA, Hollingsworth MA, Yeh JJ: Virtual microdissection identifies distinct tumor- and stroma-specific subtypes of pancreatic ductal adenocarcinoma. Nature genetics 2015;47: 1168-1178.

25 Hwang RF, Moore T, Arumugam T, Ramachandran V, Amos KD, Rivera A, Ji B, Evans DB, Logsdon CD: Cancer-associated stromal fibroblasts promote pancreatic tumor progression. Cancer Res 2008;68:918926.

26 Banerjee S, Modi S, McGinn O, Zhao X, Dudeja V, Ramakrishnan S, Saluja AK: Impaired synthesis of stromal components in response to minnelide improves vascular function, drug delivery, and survival in pancreatic cancer. Clin Cancer Res 2016;22:415425.

27 Egeblad M, Ewald AJ, Askautrud HA, Truitt ML, Welm BE, Bainbridge E, Peeters G, Krummel MF, Werb Z: Visualizing stromal cell dynamics in different tumor microenvironments by spinning disk confocal microscopy. Dis Model Mech 2008;1:155-167; discussion 165.

28 Fan M, He T, Zhang P, Zhang J, Li L: Heterogeneity of diffusion-weighted imaging in tumours and the surrounding stroma for prediction of Ki-67 proliferation status in breast cancer. Sci Rep 2017;7:2875.

29 Whiteside TL: The tumor microenvironment and its role in promoting tumor growth. Oncogene 2008;27:5904-5912.

30 Cobrinik D: Retinoblastoma Progression. EBioMedicine 2015;2:623-624.
31 Chen X, Wang J, Cao Z, Hosaka K, Jensen L, Yang H, Sun Y, Zhuang R, Liu Y, Cao Y: Invasiveness and metastasis of retinoblastoma in an orthotopic zebrafish tumor model. Sci Rep 2015;5:10351.

32 Xu XL, Lee TC, Offor N, Cheng C, Liu A, Fang Y, Jhanwar SC, Abramson DH, Cobrinik D: Tumor-associated retinal astrocytes promote retinoblastoma cell proliferation through production of IGFBP-5. Am J Pathol 2010; 177:424-435.

33 Pina Y, Boutrid H, Murray TG, Jager MJ, Cebulla CM, Schefler A, Ly LV, Alegret A, Celdran M, Feuer W, Jockovich ME: Impact of tumor-associated macrophages in LH(BETA) $\mathrm{T}(\mathrm{AG})$ mice on retinal tumor progression: relation to macrophage subtype. Invest Ophthalmol Vis Sci 2010;51:2671-2677.

34 Murray TG, Cebulla CM, Alegret A, Pina Y, Boutrid H, Jockovich ME: Targeting the tumor microenvironment as a therapeutic strategy for retinoblastoma. Invest Ophthalmol Vis Sci 2007;48:1585-1585.

35 Bond WS, Akinfenwa PY, Perlaky L, Hurwitz MY, Hurwitz RL, Chevez-Barrios P: Tumorspheres but not adherent cells derived from retinoblastoma tumors are of malignant origin. PLoS One 2013;8:e63519.

36 Braekeveldt N, Wigerup C, Tadeo I, Beckman S, Sanden C, Jonsson J, Erjefalt JS, Berbegall AP, Borjesson A, Backman T, Ora I, Navarro S, Noguera R, Gisselsson D, Pahlman S, Bexell D: Neuroblastoma patient-derived orthotopic xenografts reflect the microenvironmental hallmarks of aggressive patient tumours. Cancer Lett 2016;375:384389.

37 Batista A, Riedemann L, Vardam T, Jain RK: Targeting the tumor microenvironment to enhance pediatric brain cancer treatment. Cancer J 2015;21:307-313.

38 Houston SK, Pina Y, Clarke J, Koru-Sengul T, Scott WK, Nathanson L, Schefler AC, Murray TG: Regional and temporal differences in gene expression of LH(BETA)T(AG) retinoblastoma tumors. Invest Ophthalmol Vis Sci 2011;52:5359-5368.

39 Joyce JA, Pollard JW: Microenvironmental regulation of metastasis. Nat Rev Cancer 2009;9:239-252.

40 Maishi N, Hida K: Tumor endothelial cells accelerate tumor metastasis. Cancer Sci 2017; 108:1921-1926.
41 Kalluri R: The biology and function of fibroblasts in cancer. Nat Rev Cancer 2016;16:582598

42 Kalluri R, Zeisberg M: Fibroblasts in cancer. Nat Rev Cancer 2006;6:392-401.

43 Kidd ME, Shumaker DK, Ridge KM: The role of vimentin intermediate filaments in the progression of lung cancer. Am J Respir Cell Mol Biol 2014;50:1-6.

44 Chang Y, Li H, Guo Z: Mesenchymal stem cell-like properties in fibroblasts. Cell Physiol Biochem 2014;34:703-714.

45 Li M, Li M, Yin T, Shi H, Wen Y, Zhang B, Chen M, Xu G, Ren K, Wei Y: Targeting of cancer-associated fibroblasts enhances the efficacy of cancer chemotherapy by regulating the tumor microenvironment. Mol Med Rep 2016;13:2476-2484.

46 Qian BZ, Pollard JW: Macrophage diversity enhances tumor progression and metastasis. Cell 2010;141:39-51.

47 Allavena P, Mantovani A: Immunology in the clinic review series; focus on cancer: tumour-associated macrophages: undisputed stars of the inflammatory tumour microenvironment. Clin Exp Immunol 2012;167: 195-205.

48 Bingle L, Brown NJ, Lewis CE: The role of tumour-associated macrophages in tumour progression: implications for new anticancer therapies. J Pathol 2002;196:254-265.

49 Houston SK, Lampidis TJ, Murray TG: Models and discovery strategies for new therapies of retinoblastoma. Expert Opin Drug Discov 2013;8:383-394.

50 Lee HS, Park SW: Systemic chemotherapy in advanced pancreatic cancer. Gut Liver 2016; 10:340-347.

51 Shields CL, Bianciotto CG, Jabbour P, Ramasubramanian A, Lally SE, Griffin GC, Rosenwasser R, Shields JA: Intra-arterial chemotherapy for retinoblastoma: report No. 1, control of retinal tumors, subretinal seeds, and vitreous seeds. Arch Ophthalmol 2011;129: 1399-1406.

52 Ghassemi F, Shields CL: Intravitreal melphalan for refractory or recurrent vitreous seeding from retinoblastoma. Arch Ophthalmol 2012;130:1268-1271.

53 Munier FL, Gaillard MC, Balmer A, Soliman S, Podilsky G, Moulin AP, Beck-Popovic M: Intravitreal chemotherapy for vitreous disease in retinoblastoma revisited: from prohibition to conditional indications. $\mathrm{Br} \mathrm{J} \mathrm{Oph-}$ thalmol 2012;96:1078-1083.
Evidence of Tumour Microenvironment and Stromal Cellular Components
Ocul Oncol Pathol 2019;5:85-93

DOI: $10.1159 / 000488709$ 